\title{
POST-MEXICANOS: MÓNICA DE LA TORRE Y ROMÁN LUJÁN COMO POETAS DE FRONTERA
}

\author{
POST-MEXICANS: MÓNICA DE LA TORRE \\ AND ROMAN LUJÁN AS BORDER POETS
}

Cristián Gómez O.

Case Western Reserve University. Estados Unidos.

cgg19@case.edu

\begin{abstract}
Resumen: Este trabajo busca explorar las distintas variantes de lo que Roger Bartra identifica como postmexicanidad. Para Bartra, el nacionalismo mexicano encuentra una muralla insalvable en la globalización y los tratados de libre comercio entre México, Canadá y EE.UU., NAFTA (de acuerdo a sus siglas en inglés). Los eventos de fin de siglo y la entrada en una postmodernidad aun cuando periférica, aun así innegable, le permiten a Bartra plantear el concepto de una identidad nacional mexicana que poco o nada tiene que ver con el nacionalismo tradicional de México. En este paper buscamos trazar rasgos de esa nueva identidad en las obras de Mónica de La Torre y Román Luján, a la vez que hacer una crítica del concepto de Bartra en su parcialidad y sus exclusiones.
\end{abstract}

Palabras clave: Poesía mexicana, frontera, transnacionalidad, post-nacionalismo.

\begin{abstract}
This essay wants to explore what Mexican essayist and public figure Roger Bartra calls Post-mexican condition. According to Bartra, Mexican nationalism faces an insurmountable challenge in globalization and the Free Trade Agreement with Canada and USA (NAFTA). The turn-of-the-century of its political life and the new atmosphere brought by postmodernity, allowed Bartra to devise a concept such as post-mexicanity, a totally diverting idea from traditional Mexican nationalism. We intend to explore traces of this new kind of identity in authors like Mónica de La Torre and Roman Luján, together with a criticism of Bartra's concept due to its exclusions and limited scope.
\end{abstract}

Keywords: Mexican Poetry, border, transnationalty, post-nationalism.

Recibido: 05.08.2014. Aceptado: 06.10.2014. 


\section{Roger Bartra}

Jo otro propósito tiene este ensayo que delinear algunos de los posibles rasgos de la condición post-mexicana, tal y como la entienden, a través de su obra, autores como Mónica de la Torre (México D.F., 1969) y Román Luján (Monclova, 1975). No se trata, por cierto, de la expresión estética de un fenómeno social, ni mucho menos de la mera trasposición de un concepto en algunas obras literarias del México más reciente.

La muchas veces caprichosa forma de definir un objeto de estudio, resulta aún más antojadiza si tal objeto consiste en darle rostro y sentido a la definición de una nacionalidad, a esa esencia que de por sí se nos escapa. Tomar este reto desde el ámbito de la poesía, sólo puede agregarle un cariz de incerteza a un empeño desde un principio de incierto pronóstico. La (im)probable mexicanidad como un concepto siempre en transición ha sido ensayada en reiteradas ocasiones por una pléyade de autores de los que sólo nombraré algunos, cuyo pedigrí intelectual se resume en sus apellidos: Samuel Román, Antonio Caso, José Vasconcelos, Octavio Paz, entre algunos de los ensayistas más destacados que han abordado el tema, para no alargar la lista aquí con los nombres de todos aquellos literatos y artistas de otras disciplinas que han incursionado igualmente en este ámbito.

Roger Bartra, por su parte, revisa la noción de mexicanidad y su asociación al nacionalismo revolucionario instaurado en México con posterioridad a 1910 a través de una lupa descarnada, si bien no siempre certera. El trabajo de Bartra se basa en la crisis de legitimidad que él avizora en la vida mexicana a partir de fines de los años sesenta y cuyo gatillar se produce con la crisis política de 1982 primero, 1988 después, el sexenio de Carlos Salinas de Gortari y la rebelión zapatista del ' 94 . Todos estos son factores fundamentales para comprender lo que este sociólogo mexicano llama la condición "post-mexicana”, pero no los únicos. Para Bartra, tan importante como los anteriores, o incluso más, de acuerdo al matiz celebratorio de sus palabras, resulta ser la firma del NAFTA, el tratado de libre comercio entre Canadá, EE.UU. y el mismo México. Esa post-mexicanidad es la que nos interesa revisar a nosotros a partir de los textos de los dos poetas arriba señalados, y cómo esas estrategias textuales elaboradas desde ciertos presupuestos estético-literarios, conforman un acercamiento particular a este tema. 
Varios son los síntomas que Bartra considera indicativos del agrietamiento del modelo nacionalista revolucionario, modelo instalado una vez que la revolución mexicana comienza su consolidación y el PRI ${ }^{1}$ lograra entre las décadas del treinta y el cuarenta, que es cuando adquiere el nombre con el que se le conoce hasta hoy- un perfil que ha mantenido, con mayores o menores matices, hasta entrados los años ochenta. El más importante de aquellos síntomas consiste en el adelgazamiento de la confianza de la población mexicana en las instituciones del Estado y sus componentes políticos como portadores de un relato que legitime la representatividad, no sólo política, que en ellos se habría depositado. Las profundas sospechas sobre la transparencia electoral durante el proceso que llevó al poder a Salinas de Gortari, sumadas y en consonancia con los asesinatos, al cierre de su mandato, de Luis Donaldo Colossio y José Ruiz Massieu y el levantamiento del EZLN (Ejército Zapatista de Liberación Nacional), terminaron por rebalsar el vaso de un proceso de desgaste que llevaba décadas de gestación.

La postmodernidad como fragmentación de los paradigmas de sentido contribuye a crear un clima donde el nacionalismo como argamasa de un conjunto cada vez más heterogéneo (o que tal vez siempre fue tal, sólo que habría permanecido disimulado por las necesidades del Estado, según Bartra) entra en crisis en la medida en que la complejidad del universo social mexicano no es correspondida por el aparato burocrático e institucional que pretende abarcarla.

Sumado a lo anterior, hay que considerar los efectos incontrarrestables del proceso de globalización, que en el caso de México ha sido según el autor de La sangre y la tinta por sobre todo una norteamericanización, una influencia estadounidense mucho más que de otros lugares. Ni de lo uno ni de lo otro habría que sorprenderse, ya que estos fenómenos no son exclusivos de México, pero sí deberíamos tener muy en claro que, en este país, la globalización ha ido de la mano del neoliberalismo, del fin del rol central del Estado como factor de desarrollo, para dar paso a lo que eufemísticamente se llama "liberalización" de la economía, o en otras palabras, el ingreso del capital trasnacional a una economía definitivamente abierta a los flujos del último, como se puede comprobar con la reforma energética

\footnotetext{
${ }^{1}$ Partido Revolucionario Institucional.
} 
impulsada por el gobierno de Enrique Peña Nieto. Para ponerlo en palabras del mismo Bartra:

I think we can speak of a post-Mexican condition, not only because the NAFTA era has plunged us into so-called globalization, but primarily because the crisis of the political system hast put an end to specifically "Mexican" forms of legitimation and identity. We can understand this process better if we compare it with the fall of the Iron Curtain and the collapse of the Soviet socialist bloc. Without a doubt, "Westernizaton" -and "Americanizaton", in the Mexican case- are important effects induced from the outside, but derived from the huge internal breakdown of a complex system of legitimation and consensus (2002: 47).

Tal vez el hecho de que este texto haya sido escrito a mediados de los noventa le haya pasado la cuenta, pero me parece a mí que las metáforas del optimismo que maneja Bartra rondan la ingenuidad:

The fact that the old Mexican system finally lies dying on the sociologists' dissecting table is a cause for celebration: not only because its body is laying a bridge to democracy but also because examining its body may -as I fervently hope- spur the social sciences forward (2002: 47).

Un paréntesis en torno a las metáforas de Bartra, que no se limitan a las de su mentado optimismo. El "puente" hacia la democracia que citamos más arriba es parte de una nomenclatura llena de figuras retóricas que hacen de los textos de este sociólogo una especie de escritos híbridos (sus textos no suelen ser muy largos) que se ajustan sin problemas al ámbito más estrictamente literario.

Y volviendo al tema: no son pocos los críticos de Bartra. Muchos de ellos coinciden en subrayar el escaso interés que este autor le presta a los efectos negativos de tal apertura económica, abrazando sin mayores reparos una globalización que, vista con el paso de los años y el estado de la situación actual de México (desconocida, sin embargo, por razones obvias, para Bartra en aquel instante), no ha sido la receta del cambio que y como hubiera podido esperarse. De acuerdo a Michael P. Abeyta: 
His position is one of enthusiastic resignation with respect to postmodernism, which in my view will later reinforce his resignation with respect to neoliberalism due in large part to his failure to take sufficiently into account the negative effects of the transnational forces that have changed Mexico in the last decades (Abeyta, 2007).

Otros, como Francisco Javier López, son incluso más drásticos a la hora de señalar las lagunas de las que adolece el texto de Bartra, siendo fundamental entre ellas aquella que señala su abordaje, pobre, del tema de la guerrilla zapatista y como ésta ha enterrado el mito del mestizaje integracionista que recorriera la historia del siglo XX mexicano, el primero de los grandes símbolos de la mexicanidad que se instaurara en la conciencia colectiva del país una vez consolidado/institucionalizado el proceso revolucionario. Si quien estaba llamado a ser el crisol de esa mezcla de razas -indígena y español- era el Estado mexicano, la rebelión encabezada por el subcomandante Marcos terminó por fracturar el panorama supuestamente idílico que escondía, sin embargo, una larga historia de exclusión social y económica. El hecho de que Bartra no viera con buenos ojos la cesión de poder político a las mismas comunidades indígenas para intentar formas de semi-autogobierno, no es óbice para que todavía esperase en aquel momento el futuro con ojos auspiciosos. La caída de la nación mexicana, en ese corazón de las tinieblas que, paradójicamente, le permitiría una transición a una convivencia más democrática y receptiva de la heterogeneidad, no produjo sin embargo los frutos esperados (no obstante analizar las razones de por qué ello no llegó a buen puerto, sobrepasa los límites y los propósitos de este escrito).

Todo lo anterior no es óbice para que un concepto que subraya las nuevas formas de asumir lo nacional, incluso si se trata de su puesta entre paréntesis, no pueda iluminar ciertos aspectos de la escritura heterogénea y multiforme de autores como De la Torre y Luján, por nombrar sólo a dos de una lista mucho más extensa y que clama por una pronta "intrusión" crítica. En ese sentido, las políticas de la lengua que emprenden estos poetas son lo suficientemente elocuentes como para que su pertenencia al concepto de lo mexicano pueda ser mediada/comprendida desde el concepto de lo post-nacional. 


\section{Mónica de La Torre}

Partiré, entonces, señalando algunas estrategias de lectura en relación con la obra de Mónica de La Torre. Lo primero, por ende, sería abrir esta serie de apuntes, dispersos y desordenados en su afán de emular el proceso de mi lectura de De La Torre, subrayando que el título de este paper se debe entender como un gesto más que como un concepto, una forma de llamar la atención sobre una experiencia colectiva antes que como una propuesta de lectura definitiva.

Por lo demás, mi acercamiento a la poesía mexicana goza y sufre de mi ubicación (geográfica, pero también cultural e incluso ocupacional): soy un poeta chileno, avecindado en EE.UU., laboralmente afiliado a ese monstruo de mil caras que se conoce como "Academia norteamericana", en sus mejores y peores derivaciones. Por lo tanto, mi visión de los textos siempre le otorgará el beneficio de la duda a estos poemas ante el tribunal de sus examinadores, es decir, ante la obligatoriedad de trazar esta línea de las post-mexicanidades a partir de los textos de Mónica de La Torre, lo haré teniendo en consideración - primero y por sobre todo- que los textos de esta autora México-americana o Amero-mexicana -la denominación aquí no es gratuita- funcionan literariamente, son estéticamente productivos (Bajtín, 1982) y, por lo tanto, los posibles rasgos identitarios que estén o no en estos textos están formulados al alero de una poética que incorpora dichos rasgos, y no al revés. Debo subrayar, entonces, que este ensayo en torno a De La Torre y Luján se siente depositario de la herencia de los estudios literarios en primera instancia, para sólo desde allí explorar sus posibles coincidencias con otros campos disciplinarios. Nos valdremos, en consecuencia, de la mirada sociológica de Roger Bartra de la misma manera que este autor se vale de un lenguaje lleno de figuras literarias para concretar sus ideas, tal como señaláramos con anterioridad.

La delimitación previa no busca tanto aislar un objeto de estudio como subrayar su particularidad. Los poemas que aquí estudiamos provienen fundamentalmente de tres de los seis libros que hasta la fecha ha publicado la autora, Talk Shows (2007), Public Domain (2008) y Sociedad anónima (2010). Estos títulos, junto a Cuarenta ciudades sin nombre (2013), que recoge su anterior Acúfenos (2006), constituyen el grueso de la producción poética de De la Torre, con una característica que quisiera subrayar: son 
textos escritos algunos de ellos en inglés, otros en español. Esto, que a estas alturas no debiera constituir por sí mismo una política de la lengua, tiene, sin embargo, ciertas peculiaridades que no quisiera dejar pasar.

Primero: a diferencia de otras autoras como Gloria Anzaldúa (1987) en su libro Borderlands, De la Torre no se mueve de modo preferente entre uno y otro idioma. Aun cuando esto esté presente en sus poemarios, la opción de esta última es la de "favorecer" uno de los dos idiomas para cada uno de estos conjuntos. Se puede hablar entonces de los libros escritos en inglés y en castellano de De la Torre, pero no de un spanglish que los sitúe en ese tipo de frontera lingüística. Si quisiéramos extender la comparación, habría que decir que si la primera de estas autoras habita en la frontera, lingüística y política, entre México y EE.UU., la segunda de ellas las cruza sin que se conviertan en el centro de sus preocupaciones. Es, si se quiere, la diferencia entre una autora texana y una neoyorkina. Porque, en esto de comparar, por lo menos en sus rasgos más obvios (que no son necesariamente los que las definan), a ambas escritoras, habría entonces que señalar que el activismo político de Andalzúa no está presente en De la Torre, ese deseo chicano y reivindicativo no es un tema (abro aquí un signo de interrogación) para esta segunda autora.

Lo interesante en el caso de esta última es que ni siquiera fue percibida, por lo menos en sus primeros escarceos poéticos, como una autora mexicana. No está incluida, por ejemplo, ni en Cuerpo plural ni tampoco en El decir y el vértigo, dos antologías de poesía latinoamericana contemporánea que hicieron cierto ruido ${ }^{2}$, ni tampoco en una reunión netamente mexicana, como El manantial latente, que de una u otra forma se ha convertido en un texto de referencia para acercarse a la poesía mexicana última. Podríamos extendernos en torno a esta relación de De la Torre con su México natal (la autora es hija de padre mexicano, madre estadounidense, criada en el DF, pero con estudios universitarios y vida laboral en el país del norte durante los últimos veinte años), pero de los rasgos autobiográficos quisiéramos pasar y concentrarnos en los textuales. Entre éstos, destacar dos que no nos parecen menores.

${ }^{2}$ Tampoco está en Zurdos, de Araya y González (2004). 
Uno es la publicación de la antología bilingüe (inglés y español) Reversible Monuments, en coautoría con Michael Wiegers (2002), donde reúne la obra de poetas mexicanos nacidos con posterioridad a 1950. La otra es el "retorno" de la autora al español, con Sociedad anónima y Cuarenta ciudades sin nombre, tras publicar en inglés Talk Shows y Public Domain.

En el primero de estos libros, nos encontramos con una selección de 31 poetas mexicanos (entre los cuales De la Torre no se incluye), editada y publicada en EE.UU., con la mirada puesta en un lector norteamericano. El afán confeso de establecer puentes entre la poesía norteamericana y la mexicana, lleva a los editores de este volumen a 1) traducir un corpus considerable de autores contemporáneos y 2) a incluir, de cada uno de estos autores, una muestra extensiva, con el objetivo de que el lector pueda formarse una idea cabal de la poética de tales autores. Como señala Eliot Weinberger en la introducción de esta antología, tal vez si lo más importante de esta compilación sea el hecho de que los poetas convocados no convergen bajo el alero de un amorfo y diluido "mexicanismo", sino que, muy por el contrario, los une casi en exclusiva su raíz común en un suelo patrio, y (casi) nada más. De la diversidad de la poesía mexicana -punto con el cual estamos plenamente de acuerdo- y de las zonas en común de estos poemas podríamos hablar extensamente, pero aquí me interesa más otra de las premisas de Weinberger, la cual también compartimos aunque tal vez desde un enfoque ligeramente diferente.

Dice este ensayista y traductor norteamericano, entre otros, de Octavio Paz, que otra de las notas altas de Reversible Monuments es la evidencia de que no toda la poesía mexicana se escribe en castellano. La inclusión entre sus páginas de poetas que escriben en distintas lenguas indígenas es prueba de ello. Deberíamos agregar, por nuestra parte, dos apostillas que nos parecen fundamentales. La primera es que la poesía mexicana se escribe no sólo en castellano y en lenguas indígenas, como señala Weinberger, sino también en inglés. No sólo en castellano y en lenguas indígenas y en Spanglish, sino también inglés.

La segunda apostilla, relacionada con la anterior, dice que la poesía mexicana no se escribe sólo en México. Mónica de La Torre y Rodrigo Toscano en New York, Gaspar Orozco y Román Luján en Los Ángeles, Gabriel Jáuregui entre esta última ciudad y el DF, Omar Pimienta entre Tijuana y San Diego. Estos son ejemplos aislados que sin embargo marcan una tendencia. 
En tanto traductor y no sólo estudioso de la poesía de De la Torre, no puedo pasar por alto la situación en la que se lee su escritura. La teoría feminista de la traducción ha hecho aportes en este campo que son imprescindibles, como por ejemplo la deconstrucción de la metáfora de la fidelidad entre el original y el texto traducido. Entre el original y las bellas letras. Esta infidelidad femenina, que se reconoce sólo en tanto se reconoce la jerarquía implícita entre el primer texto y su degradada versión en la lengua de destino, es desautorizada desde la crítica más contemporánea en torno a la traducción, con el fin de equiparar ese original con su versión en otro idioma, versión que por decirlo así tiene vida propia y entra en contacto con otros textos en esa lengua de destino, modificándola y siendo al mismo tiempo modificada.

Ella misma, una consagrada traductora, en 2006 publica sus versiones de Gerardo Déniz en inglés, De la Torre le agrega un giro irónico y lúdico al hecho de vivir en transición: uno de los conceptos que más favor ha recibido en el campo de la traducción es el del "in-between", algo que no ha dejado de ser una cosa, pero sin llegar a ser la otra. El texto traducido sería ese in-between entre dos lenguas, ese poema, en el caso de nuestra autora, que ya no pertenece al inglés, pero tampoco lo hace del todo al castellano.

En el texto titulado precisamente "On translation", la reflexión se mezcla con la sutileza de ese sarcasmo que no puede ocultar una cuota de escepticismo. El primer verso de este poema ("Not to search for meaning, but to reedify a gesture, an intent", 2007: 49) es el origen de este paper, ya que su deseo de evitar un significado para subrayar un gesto y una intención, nos pone de lleno en el ámbito del texto traducido, i.e., en ese lugar entre lugares donde el sentido definitivo de una obra o un poema queda muchas veces en suspenso y lo que se traduce es antes un estilo o la sensación de un sentido antes que el sentido mismo. De hecho, el tono narrativo de la mayor del poema lo haría supuestamente "fácil" de traducir, en ausencia de figuras retóricas y/o juegos de palabras que pudieran complicar su traslado al español.

Sin embargo, una primera decisión debe ser tomada y guarda relación con el hecho de que fragmentos importantes de un poema en inglés estén escritos en español. Al verterlo a este segundo idioma, đqué hacer con estos fragmentos?, ¿dejarlos en español?, ¿traducirlos al inglés? En mi caso opté por esta última alternativa, con el anhelo de subrayar ese doble juego de los 
idiomas y de las proveniencias de la autora que de otro modo no tendría lugar en la traducción. Por lo demás, son esos fragmentos en español los que ejercen la ironía de la que habláramos antes, ese tono mitad jocoso mitad iracundo que subyace al texto. Que el poema de Paz al que se hace mención sea la repetición y la monotonía de la palabra vaca, colindante con la expresión vaca sagrada, no creo que sea una coincidencia, sobre todo dada la relación entre traductor y poeta que se produce al interior de la anécdota que narra el texto.

Es evidente, como otros de esta autora, que el poema está despojado de lirismo. La mordacidad de su mundo representado da paso, en otros textos, a descripciones igualmente carentes de cualquier asomo de lirismo (o de un lirismo entendido como la performance de una subjetividad), donde el centro de la mirada se concentra en descripciones que siguen desplegando lo incompleto de la identidad, lo tentativo de su definición. En Sociedad anónima, por ejemplo, nos encontramos con el siguiente texto que subraya el juego de las interpretaciones y la equivalencia de las mismas:

Con medias de red y vestidito rojo de cabaretera, este señor corre por las calles de Times Square con sus Nikes, no como quien corre porque se le fue el camión o porque se le hace tarde para el trabajo.

Se estará entrenando. Querrá darle mejor forma a su silueta de refrigerador.

O se habrá ido sin pagar de algún burdelillo clandestino, de algún sex shop triple X.

Tal vez sea actor y está a punto de llegar tarde a la función.

El escenario está en Broadway, eso sí. De todos los transeúntes sólo un par se inmutó (2010: 53).

Sociedad anónima está concebido como un conjunto de retratos, aunque se nos niegue la identidad de los retratados. Ordenados al azar y sin seguir ninguna cronología, podríamos decir que la voz autorial nos presenta los significantes pero nos niega los significados. Cualquiera puede ser cualquiera, la transitoriedad de las descripciones se acomoda a la fugacidad de los espacios y la hipotética identificación con ellos (2010: 62). De hecho, De 
la Torre nos dice, en una nota al final del libro, que algunos de los retratos no son obra suya, sino de un número de colaboradores que accedieron a la convocatoria hecha por la poeta. Nosotros, sin embargo, no conocemos la procedencia de los retratos, por lo que la "autoría" de cada uno de ellos permanece como un misterio. De este modo, el tema del origen y la proveniencia no encuentra un fallo, permanece indeciso ante la multiplicidad de sus fuentes.

En un correo privado que, sin embargo, estoy en condiciones de revelar, la autora se pregunta, al señalar mi interés por su mexicanidad, si este último concepto no es más que una performance. Y, en su caso, una doble performance de otredad: la mexicana en NY, la gringa en México. Agrega, además, refiriéndose a lo que llamo más arriba su falta de lirismo, lo siguiente: "Ahora bien, si el lirismo no es sino un performance de subjetividad, sin lirismo, ¿qué subjetividad se ejerce?” Esta es una pregunta crucial para entender el posicionamiento de la autora en la discusión post-nacional, puesto que una subjetividad ausente tiende a poner el dedo en la llaga respecto de qué es efectivamente lo que se despliega a través de un discurso poético. Si carece éste de una subjetividad, si no es portador, como se pregunta De La Torre, de un "mensaje" que consistiría en esa interioridad autorial, ¿̇qué hay en el poema?

No podemos, aquí y ahora, entrar en la discusión sobre cómo expresa y produce sentidos el discurso literario. Pero sí nos interesa poner de manifiesto que en ausencia de tal subjetividad unívoca y evidente, en los poemas de De La Torre se abren paso diversas subjetividades en disputa, filiaciones transitorias e identidades parcialmente asumidas que traducen, pero no transparentan, los conflictos de una postnacionalidad en medio de sociedades finiseculares como la mexicana y la estadounidense que enfrentan al mismo tiempo múltiples conflictos.

\section{Román Luján}

La escritura de ciertos autores mexicanos es la mejor expresión de ese estado in-between o entre medio, del que hablábamos más arriba, ese guión que une pero también separa dos apellidos. Entiéndaseme bien: el inmigrante latinoamericano, que llega a las fronteras del país del norte cargan- 
do muchas veces con sus apellidos paterno y materno, ve pronto que, al llenar ciertos formularios oficiales, esos que antaño eran dos apellidos son ahora uno solo, unido por un guión. A la primera reacción de natural rechazo que esta sorpresa administrativa produce, le sigue la de la incomodidad identitaria: tu nombre ha sido modificado, tu nombre ahora es otro y, bastante a menudo, será mal escrito, mal pronunciado, o ambos.

Ese limbo de la identidad es lo queremos problematizar desde la palabra poética y sus particulares dinámicas. La poesía de Román Luján presenta varias peculiaridades en torno a esta problemática que paso a detallar.

La primera de ellas es que Luján se suma a una larga lista de autores latinoamericanos que viven y escriben en EE.UU., en su caso, desde Los Ángeles, en California. Tema no menor, si se considera el alto número de inmigrantes mexicanos que viven desde hace décadas en aquella ciudad y que han desarrollado toda una cultura con raíces en México, pero también independiente de su origen, una cultura que no es del todo mexicana, pero que tampoco ha llegado a integrarse del todo al American Dream, como es la vida del mundo chicano; dentro de este contexto, lo que nos interesa particularmente de la obra de Luján es el hecho de que difícilmente su poesía puede ser calificada como chicana. No está ni escrita en inglés (como buena parte de la literatura chicana, aun cuando haya excepciones a esta norma), ni tampoco se centra, aunque tampoco lo ignore, en el anecdotario de la injusticia, en la recopilación de las reivindicaciones sociales y políticas propias de una causa como la chicana. Es, como señaláramos antes en torno a De la Torre, un ejemplo que nos parece evidente de la condición post-mexicana. Luján no se siente en la necesidad ni en la obligación de responder a los estereotipos de los que, en su momento, hablara José E. Limón:

Like similar unflattering stereotypes of other subordinate groups, those of the Chicano depict him as dirty, violent, hypersexual, treacherous, and thieving, although he also often appears as cowardly, apathetic and dormant (Limón, 1973: 258).

Tal vez sea esta falta de "militancia" lo que resulte atractivo en la poesía de Luján. Pareciera como si al asumir una ruta independiente de las demandas esperables de un autor mexicano que escribe desde EE.UU. (subrayo y entrecomillo eso de esperables), ocupase así un lugar especial dentro de la poesía escrita en español en los Estados Unidos. Sus textos, 
por lo menos, parten de ese lugar intermedio, de ese espacio no ocupado (hasta ahora).

La teoría contemporánea de la traducción ha dejado de lado cualquier jerarquía para el original, quitándole el piso a toda metáfora que quiera leer el texto traducido en términos de mayor o menor fidelidad -figura de poder, pero también de género- respecto de la lengua de origen. En su lugar, ciertos teóricos han desarrollado con felicidad el término del "in-between", es decir, la idea del texto traducido como una escritura independiente del original desde el cual toma su punto de partida, pero tampoco plenamente integrado en su lengua de destino, un texto que se mantendría extraño en el sistema que lo recibe, con el que sin embargo establecería relaciones de influencia y recepción que determinarán su vida dentro de aquel segundo sistema.

Desde nuestro punto de vista, la poesía de Román Luján respondería a cabalidad a esa figura del intermediario, del in-between. Sus textos juegan con esa indeterminación de aquello que no ha sido etiquetado, de aquello que la crítica aún no puede leer pero se empecina (o nos empecinamos) por ubicarlo dentro de nuestra taxonomía. Y es que, aun cuando Luján escriba en castellano, su poesía transita por el borde más borroso de ese español${ }^{3}$ que es como se denomina a nuestro idioma. Es, por llamarlo de alguna manera, un español en transición, pero no porque esté salpicado de anglicismos o de palabras prestadas directamente desde el inglés (como es el caso, por ejemplo, de La frontera, de Gloria Anzaldúa), sino porque necesita inventarse a sí mismo, en cada poema, para poder decir aquello que busca enunciar.

El mejor ejemplo de lo anterior es el último libro publicado por Luján, Drâstel, donde el lenguaje debe ser torcido y retorcido para representar esa realidad que es imposible de ser re/presentada sin un neologismo inédito, un vocablo que no anteceda a esa realidad, sino que, por el contrario, la inaugure. Lo sorprendente de este conjunto es su capacidad de escarbar en el intersticio, de convertir las grietas del lenguaje en una veta que puede ser explotada con beneficios insospechados.

${ }^{3}$ Precisamente así es como se conoce al idioma de todos nosotros en EE.UU., como si estuviéramos retroactivamente haciéndole caso a las políticas franquistas, tendemos en el país del norte a etiquetar a todo el idioma con un apelativo geopolítico antes que nacional, ignorando de paso toda la diversidad plurilingüística de España. 
Hay dos poemas en la obra de Luján que me parece que son los que más genuinamente expresan esa intensificación del lenguaje, su profundización vertical y su extensión horizontal. Uno de ellos es "Racimos", del libro ya citado; el otro es "Me llaman violencia", de la antología recientemente publicada Nigredo (2013). El primero es una larga lista de preguntas, que se suceden sin mayor hilación que su sucesión, una tras otra. Pero son precisamente esas preguntas las que indagan, si se quiere verticalmente, capa tras capa, en los pliegues del lenguaje, el cual, una vez es descontextualizado, demuestra su desnudez y su concreción, su materialidad, aunque no quería usar esta palabra que me parece ha sido ya demasiado socorrida cuando se intenta describir al lenguaje en su condición primera y, si cabe, original.

Como sea, la descontextualización que se opera en el referido poema de Luján tiene que ver con la perplejidad que demuestra un hablante que se encuentra en un medio extraño y ajeno, donde las palabras cobran un nuevo significado o un nuevo cariz y, en ocasiones, ninguno de los dos:

¿Por qué usan guantes blancos para hojear los pasaportes?

¿Por qué jamás se rozan en los elevadores?

¿Si caigo en dos categorías me corresponde other?

¿Y en la cama, piensan en inglés o en español?

¿Cómo van a coger si apenas se conocen?

¿Se considera todavía un café con leche o ya es un latte?

¿Extrañas más el clima o la comida?

¿Escribir es la obsesión que encuentra su forma o la forma que encuentra su obsesión?

¿Nos lo dijo María después de llevarla a la Coahuila?

¿Tantas veces en San Diego y no haber ido al zoológico?

¿Si sí sí y si no no, no? (2010: 9-11).

¿Cómo relacionar estas preguntas recicladas en versos con la mirada de Bartra?, ¿bastará con mencionar la nostalgia que sugiere la mención de esos índices de arraigo, como la comida y/o el clima, indicadores tácitos de otras formas de pertenencia más obvias y recurridas como la familia y el suelo natal, obvias y recurridas pero no por eso menos potentes? Quizás una respuesta la hallemos de inmediato en otra de las preguntas de este mismo poema ("¿Es esto un ejercicio de añoranza?¿¿Una impostación de la memoria”, 2010: 13), donde los usos de la memoria y la evocación quedan 
mediatizados en tanto forman parte de un aparato retórico, específicamente de uno poético, cuyo norte sólo se relaciona con la memoria en la medida en que se sujeta a los fines ulteriores del proyecto poético al cual pertenece, en este poema y en este libro. Pero también podríamos encontrarnos con otro acercamiento a lo post-nacional en poemas como "Bárbaro" o "Lámpara”, ya que en ellos se pone en evidencia una mirada antropológica y colonialista que aún pesa sobre esos hablantes que son vistos y entendidos como un objeto antes que un sujeto, como símbolos de una condición antes que como individuos de pleno derecho. Si en el primero de estos poemas el hablante sólo tiene derecho a hablar en tanto "nativo", es decir, como dato cuantificable, el de "Bárbaro" es cuestionado en su condición de su "ciudadano" (esto es, de integrante legal y legítimo de una comunidad) en tanto carece de los símbolos que sancionarían su pertenencia: "y esa voz/esa insufrible/jerga de serpiente/la dicción retorcida por su innoble/cuna..." (62). Es la práctica de una lengua (pero cierta práctica de cierta lengua) lo que legitima la condición de una nacionalidad o de una post-nacionalidad.

Por su parte, "Me llaman violencia" guarda ciertas similitudes con "Racimos”, al valerse también de un tono monocorde para, suponemos, subrayar la banalidad de una violencia que se ha entronizado en la cultura mexicana y, sobre todo, en la cultura mexicana de la frontera norte. El poema no es más que una lista alfabética compuesta con nombres de películas que versan sobre la violencia en México, todas protagonizadas o producidas por Mario Almada. Pero es una violencia vulgarizada, degradada, banalizada en los términos que Hannah Arendt intentó definir la violencia nazi y que aquí necesariamente debe ser reformulada, puesto que no se trata de la división del trabajo donde las piezas de la cadena productiva borran cualquier responsabilidad y decisión de quien ejerce alguna función, como alegaría Eichmann en los juicios de Nuremberg.

Nos enfrentamos, en cambio, a formas de la violencia incorporadas de tal manera al discurso social que terminan siendo invisibilizadas. La masividad del cine y la publicidad asociada al cine, la televisión y su penetración son mencionadas implícitamente en "Me llaman violencia", el cual de manera tácita refiere a esos intercambios de sur y norte a través de las películas de narcos que son incluidas aquí, pero también a través del mundo del inmigrante ilegal, los coyotes que los transportan y los Texas rangers que los vigilan. El discurso se ha reducido al mínimo y el poeta de creador se 
convierte en editor, en alguien que selecciona en lugar de escribir. No es menor ni casual la mención de la ciudad fronteriza de Tijuana. Cuando, en 1992, con un entusiasmo tal vez apresurado, García Canclini se apresuraba a celebrar la capacidad de reformular la modernidad a través del mestizaje y la hibridez, poniendo como uno de los casos más conspicuos a esta ciudad, eran pocos los que podían anticipar el ciclo de violencia en que se ha visto envuelta la frontera norte de México, pero también el sur de los Estados Unidos. Porque a la guerra por el control de las rutas del tráfico, se agrega la brutal violencia de género de la que la sociedad mexicana ha sido testigo en la última década, con cientos de mujeres asesinadas y desaparecidas, sin que casi ninguno de los culpables enfrentase nunca un tribunal.

Terminaré citando, nuevamente, los versos que mejor traducen la sensación permanente de la frontera, con todo lo que tiene de prometedor, pero también con todo lo que tiene de abandono:

¿Por qué jamás se rozan en los elevadores?

¿Y en la cama, piensan en inglés o en español?

¿Cómo van a coger si apenas se conocen?

¿Se considera todavía un café con leche o ya es un latte? (2010: 10).

Tanto Mónica de La Torre como Román Luján subrayan ese hiato por completar que es la post-mexicanidad nacida a partir de un proceso migratorio todavía en efecto. Pero lo hacen por sobre todo al tomar por asalto una institución literaria como la de México que se ha visto desbordada en sus fronteras, tanto físicas como lingüísticas, tanto reales como también las imaginarias.

\section{Referencias}

Abeyta, M. P. (2007). Postnationalism, Globalization and the "Post-Mexican Condition” in Roger Bartra. Disponible en http://forumonpublicpolicy. com/archivespring07/abeyta.pdf.

Anzaldúa, G. (1987). Borderlands/La Frontera. The New Mestiza. San Francisco: Aunt Lute Books.

Araya, P. A. y González, Y. (2004). Zurdos. Buenos Aires: Paradiso.

Bajtín, M. (1982). Estética de la creación verbal. México D.F: Siglo XXI. 
Bartra, R. (1999). La sangre y la tinta. México D.F: Océano. (2002). Blood, Ink and Culture. Miseries and Splendors of the PostMexican Condition. Durham and London: Duke University Press.

De la Torre, M. (2007). Talk Shows. Chicago: Switchback Books. (2008). Public Domain. NY: Roof Books. (2010). Sociedad anónima. México D.F: Bonobos/UNAM.

De la Torre, M. y Wiegers, M. (2002). Reversible Monuments. Washington: Copper Canyon Press.

Limón, J. E. (1973). Stereotyping and chicano resistance: An historical dimension. Aztlán, 4.2, 257-270.

Luján, R. (2010). Drâstel. México D.F.: Bonobos. (2013). Nigredo. Saltillo: Ediciones del Gobierno del Estado de Coahuila/Conaculta. 